\title{
Two-Dimensional Thin Layer Chromatography-Bioautography Designed to Separate and Locate Metabolites with Antioxidant Activity Contained on Spirulina platensis
}

\author{
Margarita Cid-Hernández, ${ }^{1}$ Fernando Antonio López Dellamary-Toral, ${ }^{2}$ \\ Luis Javier González-Ortiz, ${ }^{1}$ María Judith Sánchez-Peña, ${ }^{1}$ \\ and Fermín Paul Pacheco-Moisés (iD ${ }^{1}$ \\ ${ }^{1}$ Departamento de Química, Centro Universitario de Ciencias Exactas e Ingenierías, Universidad de Guadalajara, \\ Blvd. Marcelino García Barragán 1421, 44430 Guadalajara, Jalisco, Mexico \\ ${ }^{2}$ Departamento de Madera, Celulosa y Papel, Universidad de Guadalajara, km 15.5 de la Carretera Guadalajara-Nogales, \\ 45220 Zapopan, Jalisco, Mexico
}

Correspondence should be addressed to Fermín Paul Pacheco-Moisés; ferminpacheco@hotmail.com

Received 21 February 2018; Revised 30 April 2018; Accepted 20 June 2018; Published 5 July 2018

Academic Editor: Bogusław Buszewski

Copyright (C) 2018 Margarita Cid-Hernández et al. This is an open access article distributed under the Creative Commons Attribution License, which permits unrestricted use, distribution, and reproduction in any medium, provided the original work is properly cited.

\begin{abstract}
Spirulina platensis contains several biologically active compounds, some of them with antioxidant activity. Nevertheless, not all of these compounds have been identified to date. As a first step to achieving such identification, a methodology to perform twodimensional thin layer chromatography bioautographies on silica gel thin layer chromatography plates was proposed. Starting with a reference binary system, 5 other binary systems were tested, in which the relative polarity was systematically increased. To further improve the separation behavior, a phase modifier $\left(\mathrm{NH}_{4} \mathrm{OH}\right)$ was used. The best separation results were obtained with the isopropyl alcohol/ethyl acetate/ $\mathrm{NH}_{4} \mathrm{OH}$ ternary system. This experimental system allowed four well-resolved spots showing antioxidant activity as well as two additional areas with mixtures containing antioxidant compounds. Although the proposed methodology was designed with a specific application, it would be predictable that its field of use could be considerably greater, making the convenient modifications on the solvent polarity and "masking level" produced by the ammonium derivatives.
\end{abstract}

\section{Introduction}

Spirulina platensis is a cyanobacterium that has been used in Mexico and other countries since ancient times [1, 2]. Recently, it has attracted worldwide attention due to its potential as a protein source $[2,3]$ and its therapeutic properties (e.g., immunomodulatory functions) [4]. Spirulina contains several known antioxidants, e.g., chlorophyll a, carotenoids, phycocyanins, glutathione, tocopherol, and others [5-7]. The relative amount of these compounds, as well as the possible presence of some additional ones, mainly depends on the environmental conditions during its culture [8-11]. The antioxidant activity of Spirulina platensis or its extracts has been reported for in vitro [9-12] and in vivo [13, 14] models.
However, it is clear that such activity has been produced by relatively complex mixtures that contain an unidentified number of components, most of which could possess low or negligible antioxidant activity. Due to the high number of components potentially present in Spirulina samples, it would be predictable that, to take advantage of beneficial properties of Spirulina, the isolation and characterization of its components as much as possible will be necessary.

Thin layer chromatography (TLC) is known as a very useful technique, utilized to separate complex mixtures, whose behavior depends on the balance of hydrophobic, hydrophilic, and steric interactions, as well as hydrogen bonding, occurring between the analytes and the mobile and stationary phases [15]. The most used stationary phase 
is the silica gel [16-18], which contains $\mathrm{Si}$ atoms bonded to none, one, or two hydroxyl groups [19]. Silanol groups (Si-OH) present on silica can be reversibly dehydrated, producing a siloxane group $(\mathrm{Si}-\mathrm{O}-\mathrm{Si})$ from two $\mathrm{Si}-\mathrm{OH}$ groups [16]. Therefore, silica surface must simultaneously contain both groups, being their relative amount dependent on the amount of the cationic groups which came from the phase modifier (e.g., ammonium hydroxide or salts), which are interacting with the silanol groups, decreasing the retention trend of the stationary phase toward the metabolites that are being separated by the TLC technique [20]. Since only the $\mathrm{Si}-\mathrm{OH}$ groups are considered as strong adsorption sites $[17,21]$, the retention behavior can be externally modified (e.g., when water molecules are absorbed, preferentially on the $\mathrm{Si}-\mathrm{OH}$ groups) [22]. Thus, depending on the stationary phase characteristics, as well as the mobile phase and sample compositions, the phase modifiers (e.g., ammonium salts or derivatives) may interact with the $\mathrm{Si}-\mathrm{OH}$ groups and, therefore, modify the analytes retention behavior, especially with polar and basic compounds [18, 23].

In certain complex systems (e.g., those containing components covering a wide spectra of polarities), to improve the separation, it could be useful to simultaneously use two different chromatographic systems (e.g., different pairs of stationary phase/mobile phase). That is, a normal stationary phase (silica gel) developed with a nonaqueous mobile phase, which separates preferably nonpolar components and, in parallel, a reverse stationary phase (octadecyl silica) developed with an aqueous phase, used to separate preferably polar components $[24,25]$. However, it is clear that this methodology duplicates the human and material cost of the process, which is an important factor to be considered when the objective is to obtain a considerable mass of the isolate components (e.g., to analyze them). An alternative methodology requires the use of a dual phase TLC plate, which have allowed complex mixtures to be separated, where great separation selectivity was reached $[24,25]$. Dual phase TLC plates contain a narrow zone of $\mathrm{SiO}_{2}$ and a wide zone of octadecyl silica (or vice versa). Unfortunately, at least in North America, these multi$\mathrm{K}$ dual phase TLC plates are no longer available. Therefore, an alternative approach to effectively separate the compounds present in complex mixtures is to modify the interactions of the stationary phase, by means of the addition of a modifier to the mobile phase. Some amines have been used as phase modifiers, since they are able to mask silanol groups, reduce the silanophilic interactions with analytes, and, therefore, increase their retention factors $\left(R_{F}\right)[20,26,27]$. Furthermore, it has been reported that the chromatographic resolution is strongly affected by the $\mathrm{pK}_{\mathrm{a}}$ of the amine used. In fact, the use of basic systems promotes the separation of closely related compounds with minor structural differences [28].

On the other hand, since component(s) that are practically incompatible(s) with the mobile phase remain very close to the bottom of the thin layer chromatograms, the presence of spots containing two or more compounds at $R_{F}$ values near to zero could be possible. An equivalent statement can be expressed about components that are very compatible with the mobile phase, which migrate up to the top of the chromatogram $\left(\mathrm{R}_{\mathrm{F}}=1.0\right)$. Therefore, to avoid the multicomponent spots presence, it is commonly preferred to consider it as well resolved, only those spots clearly separated (e.g., more distributed spots through the plate) that present retention factors not very near to zero or the unit $[25,29]$.

TLC bioautography (TLC bio) is an effective and inexpensive technique that combines the chromatographic separation with in situ localization of compounds with biological activity [30-32]. The reaction between the 1,1-diphenyl-2picryl-hydrazyl (DPPH) radical and an active compound is a method commonly used to determine its antioxidant activity, which has been used to directly locate those types of compounds on TLC plates [33-37]. The characteristic reaction of this technique produces a pale yellow on the spots that contain compounds with antioxidant activity $[34,38]$.

Zarzycki et al. [33,39] implemented a one-dimensional TLC technique (1D-TLC) to separate the chemical components present in four pharmaceutical formulations of Spirulina platensis. The cyanobacterium samples were extracted with methanol, acetone, or tetrahydrofuran, obtaining the best results with methanol $[39,40]$. For all extracts, the spots on TLC plates were initially visualized using natural light and, to visualize additional spots, TLC plates were exposed to iodine vapors. Unfortunately, iodine vapors can react with some metabolites, interfering with their antioxidant activity, therefore impeding their evaluation with the DPPH technique.

The objective of this study was to provide a simple and cheap 2D-TLC biomethod for separation of compounds with antioxidant activity contained in Spirulina platensis. The ease of sample preparation, the quickness of this method, and the repeatability of the retention factors are the major novelties of this work.

\section{Experimental}

2.1. Materials and Reagents. Methanol (MeOH; Golden Bell, analytical grade), acetone (AcO; Karal, purity: 90\%), isopropyl alcohol (IOH; Fermont, purity: 99.9\%), ethyl acetate (EA; Karal, purity: 99.5\%), and n-hexane (n-Hx; Fisher Chemical, purity: 99.9\%) were distilled prior to use. Ammonium hydroxide aqueous solution (Fermont, concentration: 25-30\%) and 1,1-diphenyl-2-picrylhydrazyl (DPPH; SigmaAldrich, purity: 97\%) were used as received. TLC aluminum sheets were $20 \mathrm{~cm} \times 20 \mathrm{~cm}$ (Merck; $1 \mathrm{~mm}$ thick, silica gel $60 \mathrm{~F} 254$ ), which were heated during $30 \mathrm{~min}$ at $100^{\circ} \mathrm{C}$ in an oven (Felisa, Model 292) and maintained on a glass desiccator until their use. Spirulina platensis used for the experiments was purchased from Natura Vitalis ${ }^{\circledR} \mathrm{GmbH}$ in the form of tablets (Original spiruletten-1700 tablets; $400 \mathrm{mg}$ of Spirulina platensis/tablet).

2.2. Extract. $25 \mathrm{~g}$ of $S$. platensis tablets was crushed to fine powder using mortar and pestle and transferred into an Erlenmeyer flask containing $500 \mathrm{~mL}$ of $\mathrm{MeOH}$. This mixture was allowed to macerate for 48 hours under constant stirring. During maceration, the sample was protected from light and kept under a nitrogen atmosphere. The crude extract was filtered and concentrated with a rotary evaporator (Buchi R3) to reduce the final volume to $125 \mathrm{~mL}$. 
TABLE 1: Relative volumetric proportion for the mobile phases used to perform the 1D-TLCs and 2D-TLCs.

\begin{tabular}{lcc}
\hline Mobile phase & Solvent $1\left(\delta_{1} *\right)$ : Solvent 2 $\left(\delta_{2} *\right)$ : modifier & Relative volumetric proportion \\
\hline MP-1 & AcO $(20.3):$ n-Hx $(14.9):$ non-used & $3: 7: 0$ \\
MP-2 & AcO (20.3): n-Hx (14.9): non-used & $1: 1: 0$ \\
MP-3 & AcO (20.3): EA (18.6): non-used & $1: 1: 0$ \\
MP-4a & IOH (23.5): EA (18.6): non-used & $0.16: 1: 0$ \\
MP-4b & IOH (23.5): EA (18.6): non-used & $1: 1: 0$ \\
MP-4c & IOH (23.5): EA (18.6): non-used & $1: 0.16: 0$ \\
MP-5a & IOH (23.5): EA (18.6): $\mathrm{NH}_{4} \mathrm{OH}^{* *}$ & $0.16: 1: 0.25$ \\
MP-5b & $\mathrm{IOH} \mathrm{(23.5):} \mathrm{EA} \mathrm{(18.6):} \mathrm{NH}_{4} \mathrm{OH}^{* *}$ & $1: 1: 0.25$ \\
MP-5c & $\mathrm{IOH}(23.5):$ EA (18.6): $\mathrm{NH}_{4} \mathrm{OH}^{* *}$ & $1: 0.16: 0.25$ \\
\hline
\end{tabular}

${ }^{*}$ Solubility parameter $\left(\delta_{\mathrm{i}}\right.$; expressed in $\left.\left(\mathrm{J} / \mathrm{cm}^{3}\right)^{1 / 2}\right)[38] . * * \mathrm{pK}_{\mathrm{b}}=4.75$.

2.3. TLC Chromatography. TLC strips $(2 \mathrm{~cm} \times 10 \mathrm{~cm})$ and TLC plates $(20 \mathrm{~cm} \times 20 \mathrm{~cm})$ were used for $1 \mathrm{D}$ - and $2 \mathrm{D}$ TLC, respectively. Nine different solvent systems (Table 1) were tested as mobile phases (MPs); the MP-1 was reported previously by Zarzycki et al., which was considered as the starting mobile phase $[39,40]$.

For 1D-TLC, a cylindrical glass chamber $(10 \mathrm{~cm} \times 11 \mathrm{~cm}$; $\mathrm{D} \times \mathrm{H}$ ) was used; its temperature was kept at $30 \pm 1^{\circ} \mathrm{C}$. Ten $\mu \mathrm{L}$ of the methanolic extract was spotted near the bottom of the TLC strip. Then, the solvent of the applied extract was evaporated completely at room conditions. $15 \mathrm{~min}$ before the TLC strip was developed, ten $\mathrm{mL}$ of the correspondent MP was poured inside the chamber. Immediately, the developed strips were dried at room temperature and were photographed under visible light (VL) or ultraviolet light at $366 \mathrm{~nm}\left(\mathrm{UVL}_{366}\right)$. A Chromato-Vue CC-20 ultraviolet chromatography viewer, equipped with a UV filter from Ultra-Violet Products Inc., was used to allow the direct observation of the irradiated strips.

For 2D-TLCs, $100 \mu \mathrm{L}$ of the methanolic extract was spotted near the bottom of the TLC plate; the solvent of the applied extract was evaporated completely at room temperature. A standard TLC glass chamber (rectangular TLC developing tank complete from Aldrich; $27 \mathrm{~cm}$ x 26.5 $\mathrm{cm} \times 7.0 \mathrm{~cm}$; L x H x W) was placed inside a recirculating water bath and kept at $30 \pm 1^{\circ} \mathrm{C}$; the temperature inside the TLC chamber was monitored continuously to avoid thermal variations. $100 \mathrm{~mL}$ of the corresponding mobile phase was added to this chamber. At the end of the first development, the plate was dried at room temperature and again placed in the chamber in a perpendicular direction from the original, to be developed in a second dimension. To finish the process, the plate was dried at room temperature and the plates were photographed under $\mathrm{VL}$ and $\mathrm{UVL}_{366}$ as above.

To corroborate the repeatability of the chromatographic procedure, the 2D-TLCs were performed by quintuplicate obtaining repetitive results, evaluated by their respective $R_{F}$ values.

2.4. 2D-TLC Bioautographic Assay. In order to locate spots with probable antioxidant activity, the 2D-TLC plates were carefully dipped for 3-5 seconds in a methanolic solution of DPPH $(0.25 \mathrm{mM})$ and dried at room temperature for 30 seconds. Then, the first photographic record was taken $\left(t_{0}\right)$; subsequently, more photographs were taken each hour, for 12 hours. Additional pictures were taken every 12 hours up to 48 hours and, for the MP-5c/MP-4a system $\left(1^{\text {st }}\right.$ development $/ 2^{\text {nd }}$ development), some extra photographs were collected at longer times. Nevertheless, only the images taken at $t_{0}$ and when the spots showed maximum intensity $\left(t_{F}\right.$; for the MP1/MP-1 system, $\mathrm{t}_{\mathrm{F}}=6 \mathrm{~h}$ and, for the MP- $5 \mathrm{c} / \mathrm{MP}-4 \mathrm{a}$ one, $\mathrm{t}_{\mathrm{F}}=7$ days) are shown.

\section{Results and Discussion}

3.1. 1D-TLCs. In order to separate the compounds of the methanolic extract of Spirulina platensis, a "family" of 1DTLCs was prepared. For this purpose, just as starting point, the mobile phase used by Zarzycki et al. [39] was used, performing a systematic modification of such mobile phase to increase its relative polarity. The relative polarity of mobile phases was qualitatively estimated considering the solubility parameters of the correspondent pure solvents $(\delta)$; such criteria are commonly used to design binary solvents with a gradual decreasing of its solvation capacity [41]. This methodology considers that when the relative amount of the solvents is kept constant, using a solvent with a higher solubility parameter instead of another with a lower $\delta$ value produces a binary solvent with a higher polarity. Similarly, the polarity of the binary system increases as the relative content of the solvent with higher $\delta$ value increases [41].

Representative photographs of the TLC strips developed with the indicated mobile phases are shown in Figure 1. Under visible light, eleven spots were obtained when the MP-1 was used; this result was equivalent to the reported previously [39], demonstrating that such experiment was successfully reproduced. Besides, six additional spots were observed under $\mathrm{UVL}_{366}$. In contrast, only five additional spots were reported by Zarzycki when observed after iodine vapor exposure [39]. Nevertheless, since the well-resolved spots are especially important to this work, to establish the number of this type of spots is relevant. Thus, when analyzing the chromatograms obtained with the MP-1 (Figure 1) and their respective retention factors (Table 2), it was observed that only three well-resolved spots were obtained (since for spot \# $1, R_{F}=0.97$, there is uncertainty about whether that spot 
TABLE 2: Retention factor $\left(\mathrm{R}_{\mathrm{F}}\right)$ values of spots observed in the 1D-TLC plates, developed using the indicated mobile phases.

\begin{tabular}{|c|c|c|c|c|c|c|c|c|c|c|c|}
\hline & \multicolumn{3}{|c|}{ MP-1 } & \multicolumn{4}{|c|}{ MP-2 } & & \multicolumn{3}{|c|}{ MP-3 } \\
\hline & VL & & $\mathrm{UVL}_{366}$ & & VL & & $\mathrm{UVL}_{366}$ & & VL & & $\mathrm{UVL}_{366}$ \\
\hline 1 & 0.97 & 12 & 0.76 & 1 & 0.98 & 7 & 0.97 & 1 & 0.84 & 8 & 0.84 \\
\hline 2 & $0.93 *$ & 13 & 0.66 & 2 & 0.93 & 8 & $0.79 *$ & 2 & 0.82 & 9 & $0.71 *$ \\
\hline 3 & $0.90 *$ & 14 & 0.47 & 3 & $0.87 *$ & 9 & $0.70 *$ & 3 & 0.78 & 10 & $0.62 *$ \\
\hline 4 & $0.84 *$ & 15 & 0.41 & 4 & $0.76 *$ & 10 & $0.26 *$ & 4 & $0.68 *$ & 11 & $0.36 *$ \\
\hline 5 & 0.79 & 16 & 0.37 & 5 & 0.07 & 11 & 0.08 & 5 & $0.10 *$ & 12 & $0.13 *$ \\
\hline 6 & 0.69 & 17 & 0.07 & 6 & 0.00 & 12 & 0.03 & 6 & 0.04 & 13 & 0.04 \\
\hline 7 & 0.58 & & & & & 13 & 0 & 7 & 0.00 & 14 & 0 \\
\hline 8 & 0.50 & & & & & & & & & & \\
\hline 9 & 0.11 & & & & & & & & & & \\
\hline 10 & 0.04 & & & & & & & & & & \\
\hline 11 & 0.00 & & & & & & & & & & \\
\hline & & & & & & & & & & MP- & \\
\hline & VL & & $\mathrm{UVL}_{366}$ & & VL & & $\mathrm{UVL}_{366}$ & & VL & & $\mathrm{UVL}_{366}$ \\
\hline 1 & 0.92 & 7 & 0.92 & 1 & 0.83 & 8 & 0.83 & 1 & 0.89 & 8 & $0.81 *$ \\
\hline 2 & 0.84 & 8 & $0.79 *$ & 2 & $0.77 *$ & 9 & $0.71 *$ & 2 & 0.87 & 9 & $0.59 *$ \\
\hline 3 & $0.51 *$ & 9 & $0.23 *$ & 3 & $0.69 *$ & 10 & 0.53 & 3 & $0.77 *$ & 10 & $0.39 *$ \\
\hline 4 & $0.43 *$ & 10 & $0.19 *$ & 4 & 0.32 & 11 & 0.33 & 4 & $0.70 *$ & 11 & $0.18 *$ \\
\hline 5 & 0.07 & 11 & 0.04 & 5 & $0.11 *$ & 12 & $0.22 *$ & 5 & $0.49 *$ & 12 & 0.00 \\
\hline 6 & 0.00 & 12 & 0.00 & 6 & 0.06 & 13 & 0.07 & 6 & 0.04 & & \\
\hline & & & & 7 & 0.00 & 14 & 0 & 7 & 0 & & \\
\hline & & & & & & & & & & & \\
\hline & VL & & $\mathrm{UVL}_{366}$ & & VL & & $\mathrm{UVL}_{366}$ & & VL & & $\mathrm{UVL}_{366}$ \\
\hline 1 & 0.94 & 16 & 0.92 & 1 & 0.96 & 16 & 0.93 & 1 & 0.96 & 16 & 0.93 \\
\hline 2 & 0.92 & 17 & $0.44 *$ & 2 & 0.93 & 17 & $0.70 *$ & 2 & 0.93 & 17 & $0.70 *$ \\
\hline 3 & 0.88 & 18 & $0.37 *$ & 3 & 0.91 & 18 & 0.46 & 3 & 0.91 & 18 & $0.59 *$ \\
\hline 4 & $0.80 *$ & 19 & $0.29 *$ & 4 & $0.58 *$ & 19 & $0.38 *$ & 4 & $0.77 *$ & 19 & $0.49 *$ \\
\hline 5 & $0.41 *$ & 20 & $0.26 *$ & 5 & $0.54 *$ & 20 & 0.28 & 5 & $0.74 *$ & 20 & $0.43 *$ \\
\hline 6 & $0.36 *$ & 21 & $0.16 *$ & 6 & $0.50 *$ & 21 & $0.16 *$ & 6 & $0.68 *$ & 21 & $0.39 *$ \\
\hline 7 & $0.32 *$ & & & 7 & 0.42 & 22 & $0.09 *$ & 7 & $0.52 *$ & 22 & $0.32 *$ \\
\hline 8 & $0.24 *$ & & & 8 & $0.32 *$ & 23 & 0.00 & 8 & $0.50 *$ & 23 & 0.27 \\
\hline 9 & $0.20 *$ & & & 9 & 0.26 & & & 9 & $0.48 *$ & 24 & $0.17 *$ \\
\hline 10 & 0.13 & & & 10 & $0.21 *$ & & & 10 & $0.42 *$ & 25 & $0.04 *$ \\
\hline 11 & $0.11 *$ & & & 11 & $0.18 *$ & & & 11 & $0.38 *$ & & \\
\hline 12 & $0.10 *$ & & & 12 & $0.14 *$ & & & 12 & $0.30 *$ & & \\
\hline 13 & $0.09 *$ & & & 13 & 0.07 & & & 13 & 0.28 & & \\
\hline 14 & 0.04 & & & 14 & 0.03 & & & 14 & $0.11 *$ & & \\
\hline 15 & 0.00 & & & 15 & 0.00 & & & 15 & 0.00 & & \\
\hline
\end{tabular}

${ }^{*}$ Spots considered as well resolved.

is a pure component or a mixture [28, 29]; therefore, this spot was not considered well resolved). When the behavior shown by the other binary mobile phases is considered (Figure 1 and Table 2), it can be observed that a considerably higher number of well-resolved spots was obtained, the best results being with the MP-4c, where 7 well-resolved spots can be observed. Thus, although the highest number of total spots was obtained with the MP-1, the highest number of wellresolved spots (the goal of this work) was obtained with the MP-4c, followed by the mobile phases MP-4a and MP- 4 b.
Besides, to make a pseudo-reverse phase that allows compounds with a high polarity to be resolved more adequately, a small amount of phase modifier $\left(\mathrm{NH}_{4} \mathrm{OH}\right)$ was added to the last three systems (MP-4a, b, and c), which promoted a considerable improvement in the chromatographic separation behavior (Figure 1). Thus, the number of total spots (T), as well as the number of well-resolved spots (W) obtained with phases MP-5a $(\mathrm{T}=21$ and $\mathrm{W}=13), \mathrm{MP}-5 \mathrm{~b}(\mathrm{~T}=23$ and $\mathrm{W}=11)$, and MP-5c ( $\mathrm{T}=25$ and $\mathrm{W}=18)$, was noticeably higher than the ones obtained with the equivalent phases without phase 


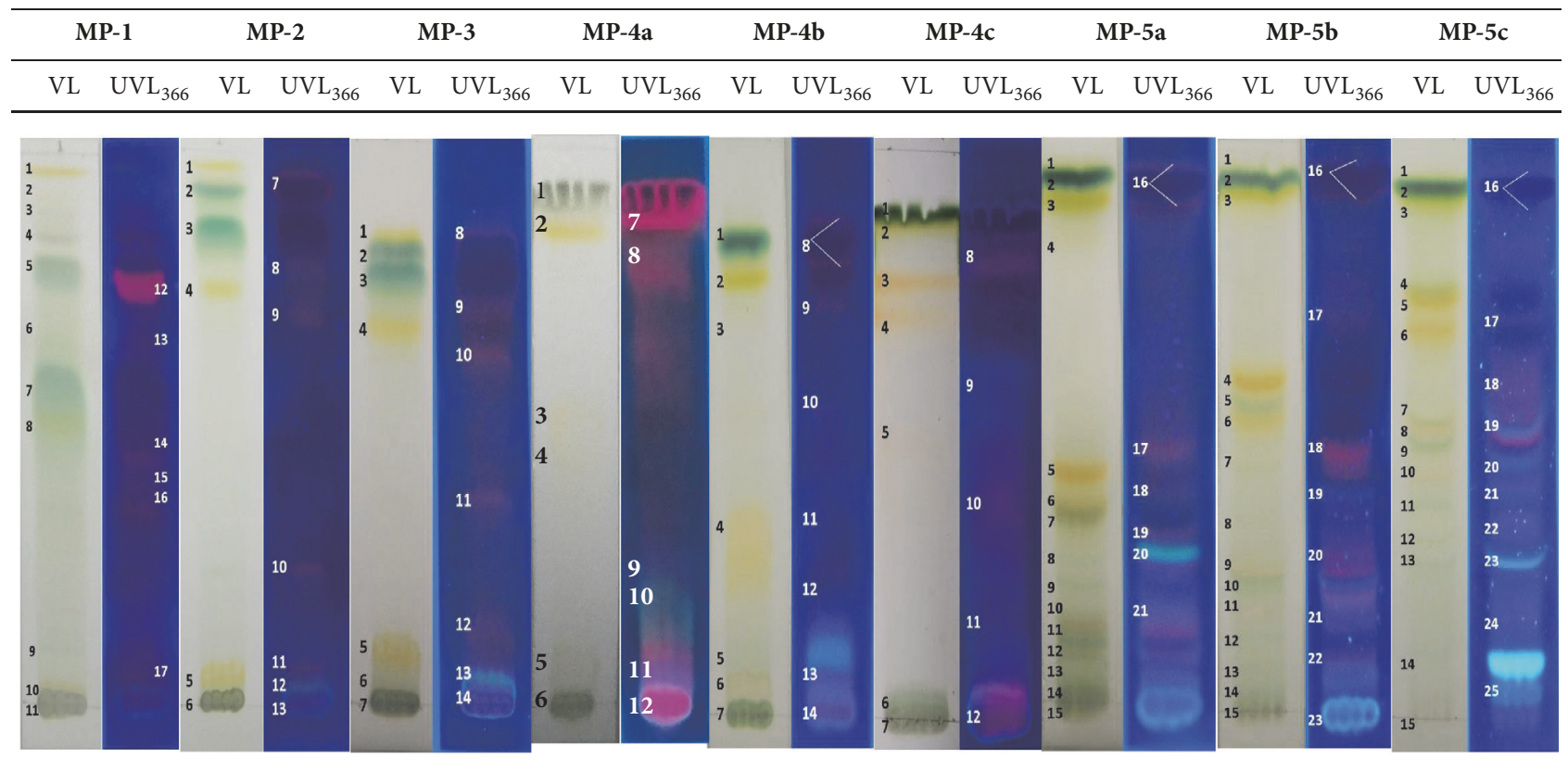

FIGURE 1: Representative photographs of 1D thin layer chromatograms for a methanolic extract of Spirulina platensis, developed with the indicated mobile phases and visualized under visible light $(\mathrm{VL})$ or under ultraviolet light $\left(\mathrm{UVL}_{366}\right)$.

modifier (MP4a: $\mathrm{T}=12$ and $\mathrm{W}=5 ; \mathrm{MP}-4 \mathrm{~b}: \mathrm{T}=14$ and $\mathrm{W}=5$; MP-4c: $\mathrm{T}=12$ and $\mathrm{W}=7)$, which demonstrate the utility of the $\mathrm{NH}_{4} \mathrm{OH}$ presence in the system (Table 2). A global analysis of the 1D-TLC results shows that, with the MP-5c, a suitable balance of the interactions among the solvent system, the stationary phase (partially masked by the $\mathrm{NH}_{4} \mathrm{OH}$ ), and the different metabolites was obtained, allowing for their gradual separation.

3.2. 2D-TLCs. To further improve the resolution of the components contained in the methanolic extract of Spirulina platensis, a wide experimental set of 2D-TLCs was performed, obtaining the best results with the system that used in the first development $\left(1^{\text {st }}\right)$ the mobile phase named MP-5c and, in the second one $\left(2^{\text {nd }}\right)$, the MP- 4 a. Thus, in Figure 2 representative photographs of chromatographic plates developed by $2 \mathrm{D}$ TLC are presented, which used the following solvent systems: (a) $1^{\text {st }}:$ MP-1 and $2^{\text {nd }}:$ MP-1 (herein referred to as the starting system) and (b) $1^{\text {st }}$ : MP-5c and $2^{\text {nd }}:$ MP-4a (herein referred to as the "best tested system"). Further, in Table 3 the corresponding $\mathrm{R}_{\mathrm{F}}$ values for such experimental systems are presented.

Regarding the separating behavior of the starting system (a system of 2D-TLC using the same mobile phase in both developments), as it could be expected $[42,43]$, the separation quality was improved by the application of the second development. Thus, in the 1D-TLC that used the MP-1, seventeen spots were obtained, but only three well-resolved spots (Figure 1), whereas in the 2D-TLC, 20 total spots could be assessed and ten of them were considered well resolved (Figure 2).

In addition, a comparative analysis of the separating behavior of the last mentioned systems (Figure 2 and Table 3 ) shows that since the "best tested system" (MP-5c/MP-4a) exhibits 28 spots, with fifteen of them being considered wellresolved spots, it can be affirmed that its separation behavior represents a considerable improvement on the chromatographic resolution, when it is compared to the starting system (MP-1/MP-1; 20 total spots and 10 well-resolved ones).

3.3. 2D-TLC Bioautographic Assays. Since the main goal of this work is to identify well-resolved spots with antioxidant activity, in a preliminary step, the yellowish characteristic produced by the DPPH technique was looked for only on the well-resolved spots (Table 3). Thus, in Figure 2 it is observed that only spots \# 6 and \# 8 are useful for providing material susceptible to being used in a subsequent identification procedure (e.g., well-resolved and containing compounds with antioxidant activity). In an equivalent analysis, but with the MP-5c/MP-4a system, a higher number of useful spots were identified, specifically, spots \#12, \#14, \#16, and \#29. It is important to mention that spot \#29 could be observed neither with visible light nor with UV light, but it could be observed when its component(s) reacted as a consequence of the DPPH addition. Taking into account only the abovementioned information, the improvement reached with the proposed 2D-TLC bioautographic assays is evident.

A more in-depth analysis of the MP-5c/MP-4a system showed in Figure 2 that although spots \# 4 (green), \#6 (more intense orange), and \#9 (less intense orange) are qualitatively distinguishable by their respective colors, they exhibit a considerable overlapped area (spot \#4 with \#6 and \#6 with \#9); therefore, they were considered not well-resolved spots. Nevertheless, after DPPH application, spot \#6 appeared very quickly (in the photo taken starting the process $\left(t_{0}\right)$ a weak yellowish color could be assessed), hinting toward a strong antioxidant activity occurring in such spot. In the case of spot 

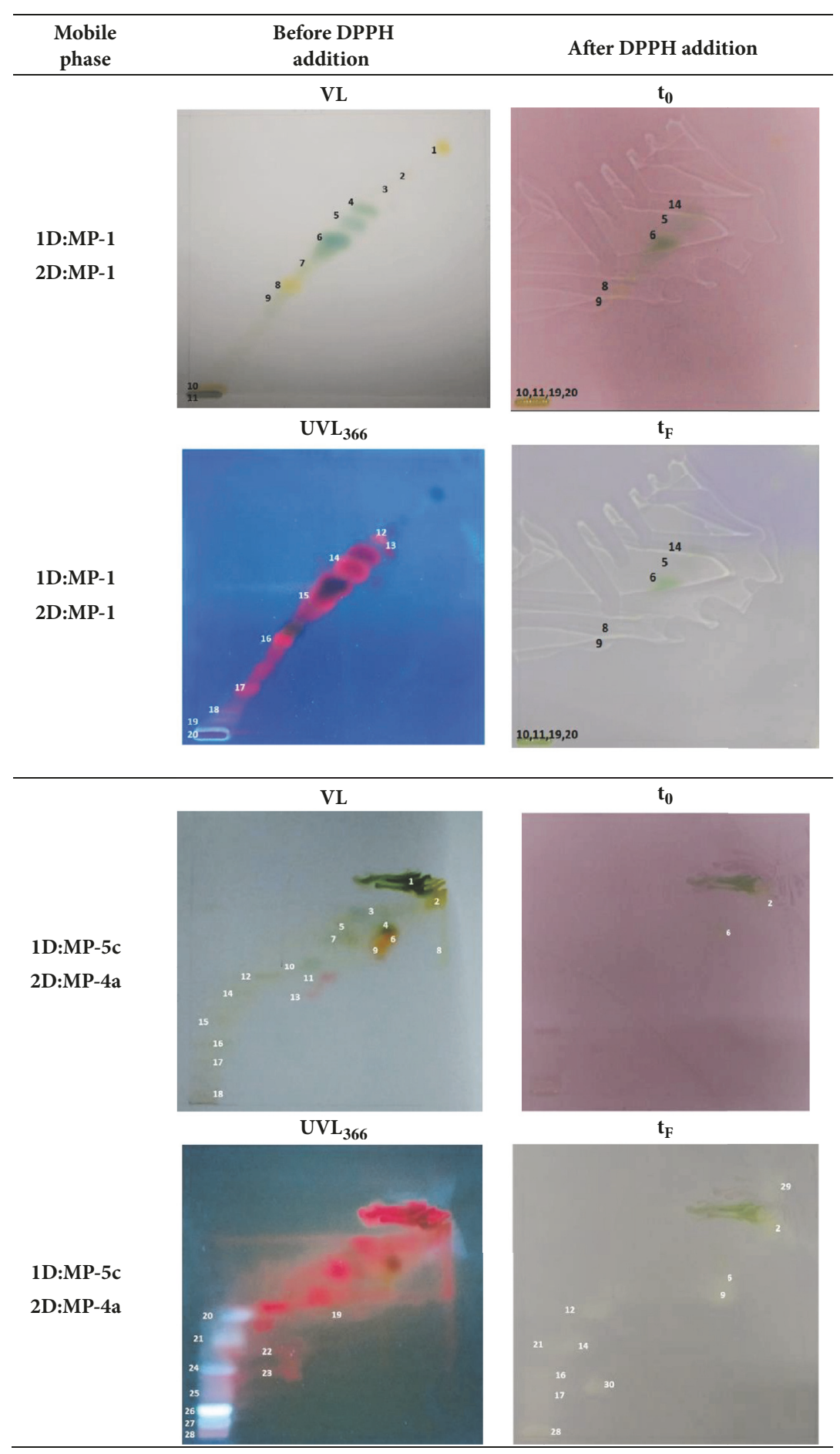

FIGURE 2: Representative photographs of 2D thin layer chromatograms for a methanolic extract of Spirulina platensis, developed with the indicated mobile phases and visualized under visible light $(\mathrm{VL})$ and under ultraviolet light $\left(\mathrm{UVL}_{366}\right)$ (central column) and the correspondent $2 \mathrm{D}$ thin layer biochromatograms, obtained after DPPH treatment at $\mathrm{t}_{0}$ and $\mathrm{t}_{\mathrm{F}}$ (right column).

\#9, its yellowish color could be assessed only after several hours, which can be interpreted as an antioxidant activity weaker than the one shown by component(s) present in spot \#6. Finally, spot \#4 never showed antioxidant activity. With such evidence, it could be useful to isolate the global area visualized in yellow in plate with DPPH to obtain a mixture containing components with a noticeable global antioxidant activity. In addition, due to spot \#28 remaining without displacement after both chromatographic developments, it was considered a non-well-resolved spot that possibly contained more than one component. Nevertheless, after the application of the DPPH, a very defined pale yellow spot appeared, which 
TABLE 3: Retention factor $\left(\mathrm{R}_{\mathrm{F}}\right)$ values observed in 2D-TLC plates, developed with the indicated mobile phases.

\begin{tabular}{|c|c|c|c|c|c|}
\hline \multirow[b]{2}{*}{ Spot } & \multicolumn{2}{|l|}{ VL } & \multicolumn{3}{|c|}{$\mathrm{UVL}_{366}$} \\
\hline & MP-1 & MP-1 & Spot & MP-1 & MP-1 \\
\hline 1 & 0.74 & $0.76 *$ & 12 & 0.59 & $0.59 *$ \\
\hline 2 & 0.66 & $0.66 *$ & 13 & 0.56 & $0.56 *$ \\
\hline 3 & 0.62 & $0.62 *$ & 14 & 0.52 & 0.49 \\
\hline 4 & 0.58 & $0.53 *$ & 15 & 0.41 & 0.38 \\
\hline 5 & 0.55 & 0.49 & 16 & 0.30 & 0.26 \\
\hline $6^{+}$ & 0.47 & $0.44 *$ & 17 & 0.15 & $0.15 *$ \\
\hline 7 & 0.38 & 0.37 & 18 & 0.06 & $0.12 *$ \\
\hline $8^{+}$ & 0.34 & $0.30 *$ & 19 & 0.04 & 0.02 \\
\hline 9 & 0.31 & 0.26 & 20 & 0.00 & 0.00 \\
\hline 10 & 0.03 & 0.02 & & & \\
\hline \multirow[t]{2}{*}{11} & 0.00 & 0.00 & & & \\
\hline & MP-5c & MP-4a & & MP-5c & Mp-4a \\
\hline 1 & 0.79 & 0.79 & 19 & 0.46 & 0.59 \\
\hline 2 & 0.74 & 0.86 & 20 & 0.46 & $0.09 *$ \\
\hline 3 & 0.68 & $0.59 *$ & 21 & 0.38 & $0.06 *$ \\
\hline 4 & 0.64 & 0.69 & 22 & 0.34 & 0.35 \\
\hline 5 & 0.64 & $0.54 *$ & 23 & 0.26 & 0.35 \\
\hline 6 & 0.60 & 0.71 & 24 & 0.26 & $0.03 *$ \\
\hline 7 & 0.60 & $0.53 *$ & 25 & 0.16 & 0.02 \\
\hline 8 & 0.56 & $0.88 *$ & 26 & 0.11 & $0.00 *$ \\
\hline 9 & 0.56 & 0.68 & 27 & 0.05 & $0.00 *$ \\
\hline 10 & 0.50 & $0.43 *$ & 28 & 0.00 & 0.00 \\
\hline 11 & 0.45 & 0.48 & $29^{+}$ & 0.20 & 0.26 \\
\hline $12^{+}$ & 0.45 & $0.29 *$ & & & \\
\hline 13 & 0.38 & $0.43 *$ & & & \\
\hline $14^{+}$ & 0.38 & $0.18 *$ & & & \\
\hline 15 & 0.30 & $0.09 *$ & & & \\
\hline $16^{+}$ & 0.22 & $0.00 *$ & & & \\
\hline 17 & 0.15 & 0.00 & & & \\
\hline 18 & 0.04 & 0.00 & & & \\
\hline
\end{tabular}

* Spots considered as well resolved.

${ }^{+}$Spots considered as well-resolved and containing compounds with antioxidant activity.

demonstrates that, regardless of the number of components, it is a mixture (or a pure component) potentially useful thanks to its antioxidant activity.

\section{Conclusion}

As a first step in the identification of the antioxidant compounds contained in methanolic extracts of Spirulina platensis, a simple and fast 2D-TLC biosystem was developed. The proposed experimental system allowed a suitable separation and localization of such type of components, whose dispersion on the plate was favored by the use of $\mathrm{NH}_{4} \mathrm{OH}$ as a phase modifier. The last system was intentionally designed to be scaled to preparative TLC plates, which is a preliminary stage to the identification of components; at this time, we are working on that stage.

\section{Data Availability}

The data used to support the findings of this study are available from the corresponding author upon request.

\section{Conflicts of Interest}

The authors declare that they have no conflicts of interest.

\section{References}

[1] G. Abdulqader, L. Barsanti, and M. R. Tredici, "Harvest of Arthrospira platensis from Lake Kossorom (Chad) and its household usage among the Kanembu," Journal of Applied Phycology, vol. 12, no. 3-5, pp. 493-498, 2000.

[2] O. Ciferri, "Spirulina, the edible microorganism," Microbiology and Molecular Biology Reviews, vol. 47, no. 4, pp. 551-578, 1983. 
[3] E. W. Becker, "Micro-algae as a source of protein," Biotechnology Advances, vol. 25, no. 2, pp. 207-210, 2007.

[4] Z. Khan, P. Bhadouria, and P. S. Bisen, "Nutritional and therapeutic potential of Spirulina," Current Pharmaceutical Biotechnology, vol. 6, no. 5, pp. 373-379, 2005.

[5] S. K. Ali and A. M. Saleh, "Spirulina - An overview," International Journal of Pharmacy and Pharmaceutical Sciences, vol. 4, pp. 9-15, 2012.

[6] E. W. Becker and L. V. Venkataraman, "Production and utilization of the blue-green alga Spirulina in India," Biomass, vol. 4, no. 2, pp. 105-125, 1984.

[7] E. Ross and W. Dominy, "The Nutritional Value of Dehydrated, Blue-Green Algae (Spirulina plantensis) for Poultry," Poultry Science, vol. 69, no. 5, pp. 794-800, 1990.

[8] J. C. M. Carvalho, F. R. Francisco, K. A. Almeida, S. Sato, and A. Converti, "Cultivation of Arthrospira (Spirulina) platensis (Cyanophyceae) by fed-batch addition of ammonium chloride at exponentially increasing feeding rates," Journal of Phycology, vol. 40, no. 3, pp. 589-597, 2004.

[9] L. M. Colla, E. B. Furlong, and J. A. V. Costa, "Antioxidant properties of Spirulina (Arthospira) platensis cultivated under different temperatures and nitrogen regimes," Brazilian Archives of Biology and Technology, vol. 50, no. 1, pp. 161-167, 2007.

[10] K. Kim, D. Hoh, Y. Ji, H. Do, B. Lee, and W. Holzapfel, "Impact of light intensity, $\mathrm{CO} 2$ concentration and bubble size on growth and fatty acid composition of Arthrospira (Spirulina) platensis KMMCC CY-007," Biomass \& Bioenergy, vol. 49, pp. 181-187, 2013.

[11] S. Benelhadj, A. Gharsallaoui, P. Degraeve, H. Attia, and D. Ghorbel, "Effect of $\mathrm{pH}$ on the functional properties of Arthrospira (Spirulina) platensis protein isolate," Food Chemistry, vol. 194, Article ID 18081, pp. 1056-1063, 2016.

[12] P. Bermejo-Bescós, E. Piñero-Estrada, and Á. M. Villar del Fresno, "Neuroprotection by Spirulina platensis protean extract and phycocyanin against iron-induced toxicity in SH-SY5Y neuroblastoma cells," Toxicology in Vitro, vol. 22, no. 6, pp. 14961502, 2008.

[13] N. Kumar, S. Singh, N. Patro, and I. Patro, "Evaluation of protective efficacy of Spirulina platensis against collagen-induced arthritis in rats," Inflammopharmacology, vol. 17, no. 3, pp. 181190, 2009.

[14] A. Karadeniz, M. Cemek, and N. Simsek, "The effects of Panax ginseng and Spirulina platensis on hepatotoxicity induced by cadmium in rats," Ecotoxicology and Environmental Safety, vol. 72, no. 1, pp. 231-235, 2009.

[15] A. Méndez, E. Bosch, M. Rosés, and U. D. Neue, "Comparison of the acidity of residual silanol groups in several liquid chromatography columns," Journal of Chromatography A, vol. 986, no. 1, pp. 33-44, 2003.

[16] G. B. Cox, "The influence of silica structure on reversed-phase retention," Journal of Chromatography A, vol. 656, no. 1-2, pp. 353-367, 1993.

[17] S. D. Rogers and J. G. Dorsey, "Chromatographic silanol activity test procedures: The quest for a universal test," Journal of Chromatography A, vol. 892, no. 1-2, pp. 57-65, 2000.

[18] S. Bocian and B. Buszewski, "Residual silanols at reversed-phase silica in HPLC - A contribution for a better understanding," Journal of Separation Science, vol. 35, no. 10-11, pp. 1191-1200, 2012.

[19] M. C. García-Alvarez-Coque, G. Ramis-Ramos, and J. J. BaezaBaeza, "Reversed phase liquid chromatography," in Analytical
Separation Science, vol. 1, pp. 159-198, Wiley, New York, NY, USA, 2015.

[20] S. Calabuig-Hernández, M. C. García-Alvarez-Coque, and M. J. Ruiz-Angel, "Performance of amines as silanol suppressors in reversed-phase liquid chromatography," Journal of Chromatography A, vol. 1465, pp. 98-106, 2016.

[21] R. P. W. Scott and P. Kucera, "Some aspects of the chromatographic properties of thermally modified silica gel," Journal of Chromatographic Science (JCS), vol. 13, no. 7, pp. 337-346, 1975.

[22] M. L. Hair and W. Hertl, "Adsorption on hydroxylated silica surfaces," The Journal of Physical Chemistry C, vol. 73, no. 12, pp. 4269-4276, 1969.

[23] S. R. Cole and J. G. Dorsey, "Cyclohexylamine Additives for Enhanced Peptide Separations in Reversed Phase Liquid Chromatography," Biomed. Chromatogr, vol. 1, p. pp, 1997.

[24] T. Tuzimski and E. Soczewiński, "Correlation of retention parameters of pesticides in normal- and reversed-phase systems and their utilization for the separation of a mixture of 14 triazines and urea herbicides by means of two-dimensional thin-layer chromatography," Journal of Chromatography A, vol. 961, no. 2, pp. 277-283, 2002.

[25] T. Tuzimski and E. Soczewinski, "Use of a database of plots of pesticide retention (RF) against mobile-phase composition. Part I. Correlation of pesticide retention data in normal- and reversed-phase systems and their use to separate a mixture of ten pesticides by 2D TLC," Chromatographia, vol. 56, no. 3-4, pp. 219-223, 2002.

[26] A. Nahum and C. Horváth, "Surface silanols in silica-bonded hydrocarbonaceous stationary phases. I. Dual retention mechanism in reversed-phase chromatography," Journal of Chromatography A, vol. 203, no. C, pp. 53-63, 1981.

[27] K. E. Bij, C. Horváth, W. R. Melander, and A. Nahum, "Surface silanols in silica-bonded hydrocarbonaceous stationary phases. II. Irregular retetion behavior and efect of silanol masking," Journal of Chromatography A, vol. 203, pp. 65-84, 1981.

[28] A. Wehrli, J. C. Hildenbrand, H. P. Keller, R. Stampfli, and R. W. Frei, "Influence of organic bases on the stability and separation properties of reversed-phase chemically bonded silica gels," Journal of Chromatography A, vol. 149, no. C, pp. 199-210, 1978.

[29] C. Meyers and D. Meyers, Thin-Layer Chromatography, in Current Protocols in Nucleic Acid Chemistry, John Wiley \& Sons, Inc, Hoboken, NJ, USA.

[30] L. Zhang, J. Shi, J. Tang et al., "Direct coupling of thin-layer chromatography-bioautography with electrostatic field induced spray ionization-mass spectrometry for separation and identification of lipase inhibitors in lotus leaves," Analytica Chimica Acta, vol. 967, pp. 52-58, 2017.

[31] M. Jamshidi-Aidji and G. E. Morlock, "Bioprofiling of unknown antibiotics in herbal extracts: Development of a streamlined direct bioautography using Bacillus subtilis linked to mass spectrometry," Journal of Chromatography A, vol. 1420, pp. 110118, 2015.

[32] A. Marston, "Thin-layer chromatography with biological detection in phytochemistry," Journal of Chromatography A, vol. 1218, no. 19, pp. 2676-2683, 2011.

[33] B. K. Głód, P. M. Wantusiak, P. Piszcz, E. Lewczuk, and P. K. Zarzycki, "Application of micro-TLC to the total antioxidant potential (TAP) measurement," Food Chemistry, vol. 173, pp. 749-754, 2015.

[34] L. Gu, T. Wu, and Z. Wang, "TLC bioautography-guided isolation of antioxidants from fruit of Perilla frutescens var. acuta," 
LWT - Food Science and Technology, vol. 42, no. 1, pp. 131-136, 2009.

[35] Ł. Cieśla, J. Kryszeń, A. Stochmal, W. Oleszek, and M. Waksmundzka-Hajnos, "Approach to develop a standardized TLC-DPPH test for assessing free radical scavenging properties of selected phenolic compounds," Journal of Pharmaceutical and Biomedical Analysis, vol. 70, pp. 126-135, 2012.

[36] P. Molyneux, "The use of the stable free radical diphenylpicrylhydrazyl (DPPH) for estimating antioxidant activity Philip," Songklanakarin Journal of Science and Technology, vol. 26, pp. 211-219, 2004, http://pubsonline.informs.org/doi/abs/10.1287/ isre.6.2.144.

[37] W. Brand-Williams, M. E. Cuvelier, and C. Berset, "Use of a free radical method to evaluate antioxidant activity," LWT - Food Science and Technology, vol. 28, no. 1, pp. 25-30, 1995.

[38] M. S. Blois, "Antioxidant determinations by the use of a stable free radical," Nature, vol. 181, no. 4617, pp. 1199-1200, 1958.

[39] P. K. Zarzycki, M. B. Zarzycka, V. L. Clifton, J. Adamski, and B. K. Głód, "Low-parachor solvents extraction and thermostated micro-thin-layer chromatography separation for fast screening and classification of spirulina from pharmaceutical formulations and food samples," Journal of Chromatography A, vol. 1218, no. 33, pp. 5694-5704, 2011.

[40] P. K. Zarzycki, M. M. Ślaogonekczka, M. B. Zarzycka, E. Włodarczyk, and M. J. Baran, "Application of micro-thin-layer chromatography as a simple fractionation tool for fast screening of raw extracts derived from complex biological, pharmaceutical and environmental samples," Analytica Chimica Acta, vol. 688, no. 2, pp. 168-174, 2011.

[41] F. Francuskiewicz, "Appendix," in Polymer Fractionation, pp. 189-191, Springer-Verlag, Berlin, Germany, 1994.

[42] B. Spangenberg, C. F. Poole, and C. Weins, "Theoretical Basis of Thin Layer Chromatography (TLC)," in Quantitative Thin-Layer Chromatography, pp. 13-52, Springer Berlin Heidelberg, Berlin, Germany, 2010.

[43] P. K. Zarzycki, "Simple horizontal chamber for thermostated micro-thin-layer chromatography," Journal of Chromatography A, vol. 1187, no. 1-2, pp. 250-259, 2008. 

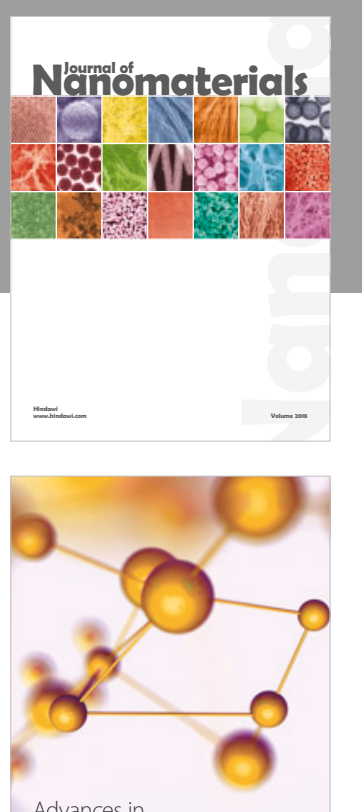

Physical Chemistry
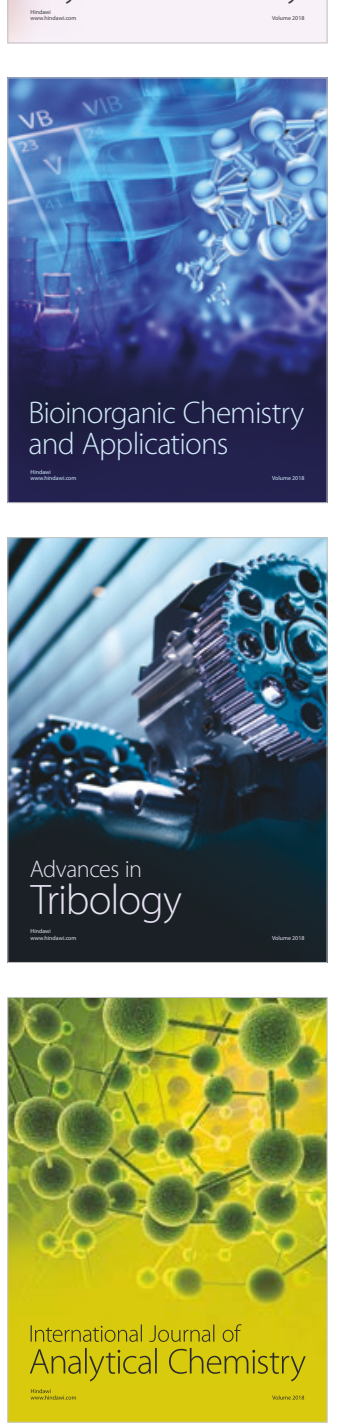

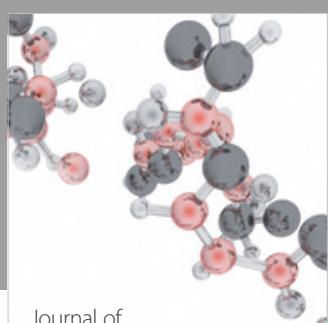

Analytical Methods

in Chemistry

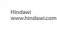

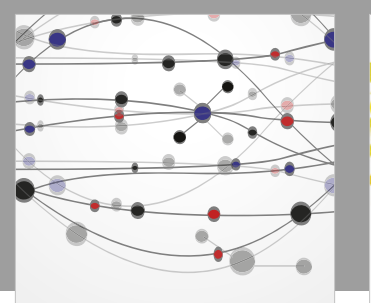

The Scientific World Journal

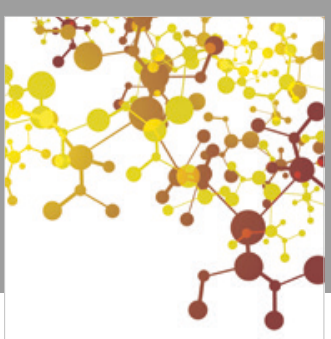

Journal of

Applied Chemistry
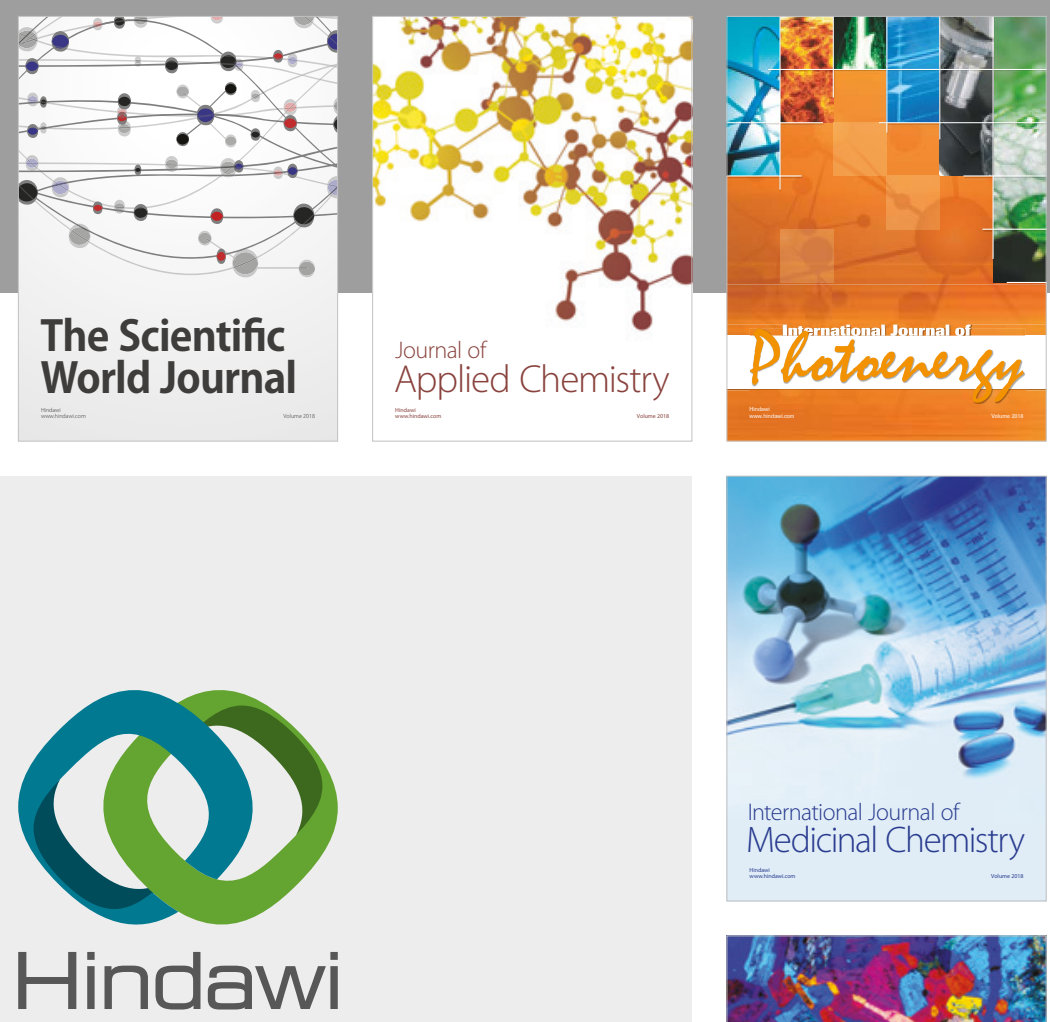

Submit your manuscripts at

www.hindawi.com
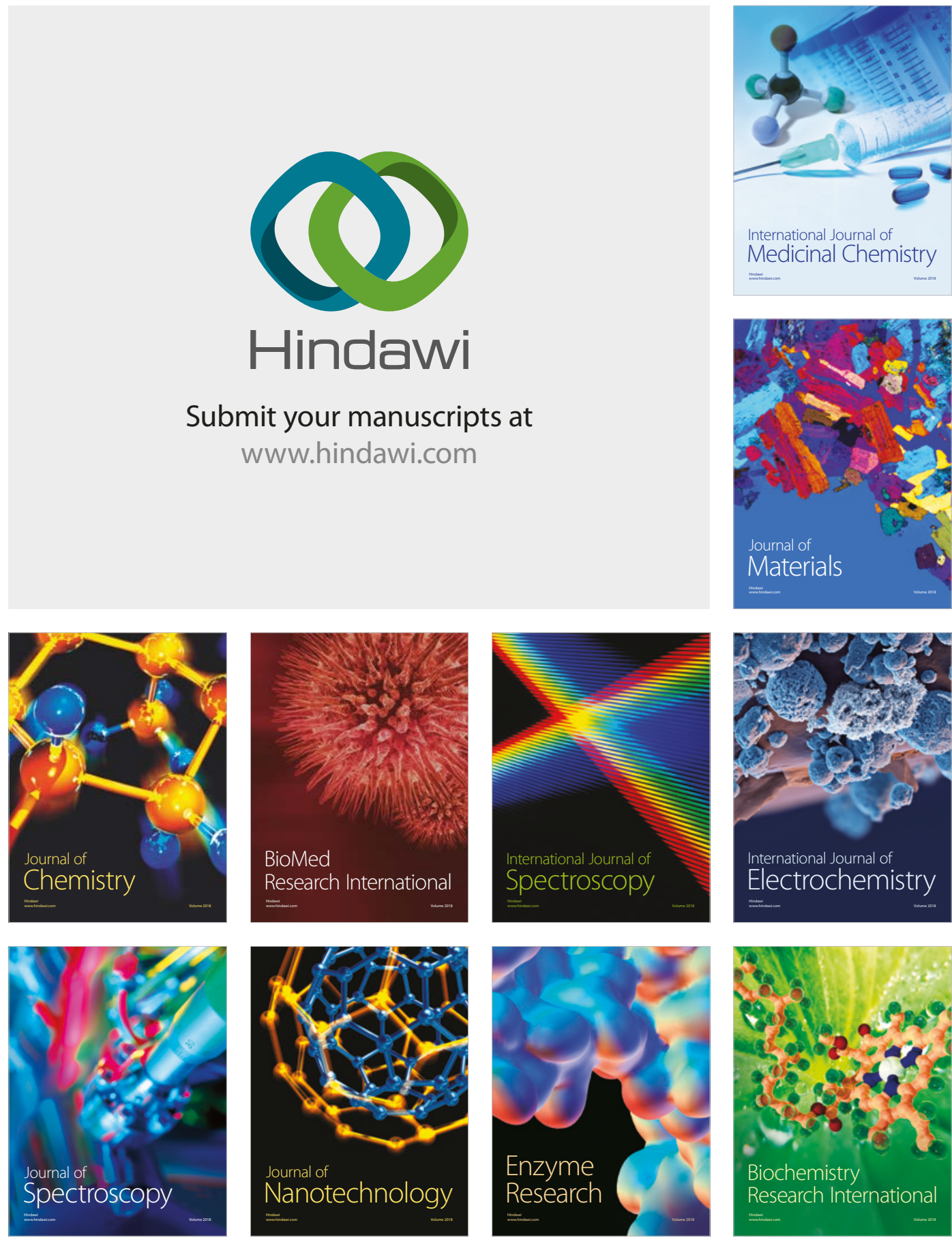
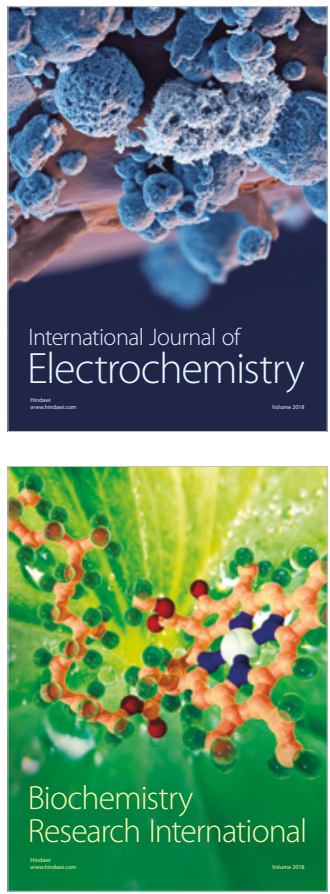